\title{
Benefits of Virtual Pedagogical Characters - A Learning Style Perspective
}

\author{
Agneta Gulz* and Magnus Haake
}

Lund University Cognitive Science, Sweden

\begin{abstract}
The article explores the relation between i) the attitudes of students towards digital pedagogical characters and ii) their learning style as separate versus connected thinkers, a learning style dimension which regards individual's approach towards the social dimensions of knowledge. Ninety 12-15 year old students participated in the study in which they were presented with a scenario-based multimedia program. In this program the student is to take the role of a journalist at a magazine that is sent on various missions to European countries in order to conduct article research. The journalist is accompanied by a digital pedagogical character in the form of a virtual instructor or a virtual learning companion.

After having progressed through the introductory parts of the program, including a module for choosing a visual character to represent their virtual instructor or learning companion, the students were (among other things) asked about their views on the idea of using virtual pedagogical characters as an enhancement of learning environment. Furthermore, they were presented with an option between two digital characters with different communicative styles - one strictly task oriented and one task and relation oriented and were asked to give motives for their choice. The students were also asked to fill out a learning style inventory addressing separate versus connected thinking.

The results of the study confirm what has been shown in some other studies, namely that there are considerable individual differences both in attitudes towards digital characters in digital learning environments and in attitudes towards the social orientation of such characters, and that these differences in attitudes may be related to various user characteristics. More specifically, the results of the current study indicate that differences in learning style of the kind assessed in the study belong among those user characteristics. The results are finally discussed in terms of practical implications for the use and design of digital learning environments.
\end{abstract}

Keywords: Learning style, separate versus connected thinker, social dimension of knowledge, digital character.

\section{INTRODUCTION}

\subsection{Digital Characters and the Social Dimension of Digi- tal Learning Environments}

Current understandings of learning depend on an acceptance of the role that social aspects play for successful learning [1-3]. In line with seminal psychologists such as Vygotsky, Piaget and Bandura, it is often emphasized that knowledge is socially constructed and that learning processes essentially involve communication and negotiation with other social actors. Also from a cognitive science perspective, the rich ability to process various forms of social information as well as the motivation to do so, are considered essential for human intellectual activities [4].

When dealing with digital learning environments, it is suggested that one way to develop or strengthen a social dimension is via digital pedagogical characters that can interact with learners [5-7]. Kim \& Baylor [8] argue that digital pedagogical characters may provide what traditional computer-based learning environments often fail to provide, namely situated social interaction.

In the following we will refer to character enhancement when an electronic environment is endowed with a digital

*Address correspondence to this author at the Lund University Cognitive Science, Sweden; Tel: +46-46-2223269; Fax: +46-46-2224424;

E-mail: agneta.gulz@lucs.lu.se character or digital characters [9]. Some characters are animated. In these a social dimension can be represented by movements, gestures, and facial expressions as well as by voice, dialogue, etc. Examples are Herman the Bug [10] and the characters in FearNot [11]. Other digital characters are not, or very limitedly, animated. As an example, the personalities of Hietala \& Niemirepo's [12] learning companion agents are comprised of a name, a picture, and a personal voice and manner of speech, that are exploited as social features.

Virtual pedagogical characters also differ in other ways than the degree of animation. Central to this paper is the distinction between a strictly task oriented pedagogical character and a relation and task oriented pedagogical character. A strictly task oriented pedagogical character sticks closely to the actual task, focuses on factuality and provides information in a succinct and objective manner. A relation and task oriented ${ }^{1}$ pedagogical character in addition to contributing to the solving of the learning task, also works on developing a social relationship with the learner. Such a character personalizes the task, is more subjective, and focuses less strictly on the task in the dialogue, which may also contain small-talk, conversational storytelling, getting-acquaintedtalk, joke-telling, sharing of personal experiences, preferences and opinions, etc. Also voice features typically differ. For instance, there is typically more warmth and expressiveness, more reinforcing interjections such as "mm-hmmm"

\footnotetext{
${ }^{1}$ Henceforth shortened to "relation oriented".
} 
and more variation in pitch, amplitude and tempo associated with the relation orientation [13]. When characters are animated, a variety of non-verbal behaviour may be involved in shaping the two pedagogical approaches; with for instance more smiling, nodding and emotional gesturing in the relation oriented approach (ibid.).

The main purpose of the study reported in this paper was to study learner responses and attitudes (i) towards character enhancement of pedagogical environments, and specifically (ii) towards character enhancement that involves relation oriented pedagogical characters. The underlying quest regarded the degree of homogeneity in responses and attitudes.

\subsection{How Homogenous are the Positive Effects of Virtual Pedagogical Characters?}

On a general level, the description of human beings as tuned to social interaction and social information is well supported, and so is, consequently, the idea that character enhancement of digital learning environments, in particular the supplying of relation oriented characters, can be beneficial to learning. There are also indeed a number of studies that show positive effects: both motivational effects $[14,15]$ and effects on learning performance $[6,16]$.

But the questions we pose are:

- How unison is the picture?

- How unitary are the benefits in terms of increased motivation and engagement and/or learning performance in a population of learners?

- If there is variability, can one identify user characteristics that influence to what extent virtual pedagogical characters, and relation oriented characters in particular, have positive or not so positive effects?

Robertson and collaborators [17] hold forth that it is "likely that users in different target user groups have different attitudes towards agents" (ibid., p.336). Bickmore and Cassell [18] observe that already "several studies have shown that users react differently to social agents based on their own personality and other dispositional traits" (ibid., p.12-13).

Among the user characteristics that have been taken into account in these studies are passive versus active [18], introvert versus extrovert [12, 18] and control orientation [19]. Out of these characteristics, both introversion-extroversion and passiveness-activeness are related to attitudes towards social relationships and social aspects of information. For the study to be presented we have, as well, chosen a user characteristic that relates to attitudes towards social relations and social aspects of information, but which is furthermore a characteristic that is more explicitly related to attitudes towards knowledge. The reason for this choice is to increase the relevance for a learning context. The user characteristic in question regards connected versus separate approaches towards knowledge as described by Galotti, Clinchy, Ainsworth, Lavin \& Mansfield [20] and assessed by the ATTLS ${ }^{2}$ inventory (ibid.). In brief this regards the extent to which a learner approaches knowledge and learning in an objective, analytical and detached manner versus in a personal, holistic

\footnotetext{
${ }^{2}$ Attitudes toward thinking and learning scale.
}

and contextually engaged way. More details will be presented further on in the text.

This user characteristic is also - in our vocabulary - an example of cognitive style or learning style. By cognitive style we refer to peoples' preferred ways of thinking and approaching information: how they tend to think and to process information ([21] thinking style). Learning style refers to how they tend to think and approach information in contexts of learning [22].

\subsection{Target Questions}

The following were the target questions that we set up for our study: ${ }^{3}$

a) What attitudes towards the general idea of virtual pedagogical characters will participants express?

b) What attitudes towards relation oriented pedagogical characters will they express?

c) If any significant differences between groups of participants are identified in a) or b) above, can these differences be related to differences in cognitive style as assessed by the instrument, the ATTLS inventory, used in the study?

Before we present the study we will discuss some related previous studies.

\section{PREVIOUS STUDIES SHOWING DIVERGENT USER RESPONSES}

Four studies are described below. The first two concern user responses towards character enhancement in general. The following two additionally involve user responses towards relation oriented characters. All studies, furthermore, attempt to relate these varying user responses to some form of user characteristics, such as locus of control, age, gender, introversion-extroversion, etc.

\subsection{A Character Enhanced Web-Browser}

Rickenberg \& Reeves [19] studied the likeability of three different web-browsers: one without an animated character, another with a character not interacting very much with the user and a third with a character monitoring and interacting with the user to a greater extent. The likeability was assessed through a number of Likert scales regarding levels of enjoyment, fun, and boredom as well as willingness to recommend and expected future use of such a system.

The study involved a grouping of the participants into those with high internal locus of control who tend to think that they control their own success, and those with low internal locus of control who tends to think that other people control their success ${ }^{4}$. The results showed large variability where locus of control turned out to have a significant main effect. Participants with internal control orientation liked the browser without character more than the browser with a monitoring character, and as much as the browser with an idle character. Participants with external control orientation, to the contrary, liked the character enriched browsers most,

\footnotetext{
${ }^{3}$ That is, the study as related to the focus of this article. A number of other issues were explored as well in the study and are reported elsewhere [23-25].

${ }^{4}$ The grouping was done by means of Rotter's Locus of Control Scale.
} 
both when the character was idle, and - in particular - when the character was monitoring. The authors suggest that the concept of locus of control could help to separate those who like from those who do not like animated characters.

\subsection{A Character Enhanced Intelligent Tutoring System that Supports Creative Writing}

Robertson Cross, Macleod \& Wiemer-Hastings [17] present findings of a field study where 60 10-12-year-old pupils got to use StoryStation, a system that supports creative writing by giving feedback on aspects such as vocabulary usage, person characterization skills and spelling. Half the group used the agent version of the system, where feedback was presented via animated characters, and half the group used the non-agent version of the system, where exactly the same feedback was presented in text boxes on a more traditional graphical user interface.

Overall, both groups indicated that they enjoyed using StoryStation very much, but some patterns of divergences were found. An analysis of questionnaire data by group and gender suggested that the oldest age group of boys (12-yearolds) responded least well to the agents. Some boys noted during the interviews that they would prefer cartoon style characters such as Bart Simpson or characters from the Beans. Others remarked that the characters looked as if they were "for kids", and commented that their younger brothers or sisters might like to use them. One twelve-year-old boy from the StoryStation design team said "Well, you wouldn't want your friends to see you playing with the helpers on screen. They'd laugh at you." (ibid., p.355).

\subsection{A Character Enhanced Electronic Estate Agency}

Bickmore [13] reports user studies with the character REA who has the role of a real estate agent, interviewing potential home buyers and showing them around houses. REA comes in two versions. In the strictly task oriented version 5 she is purely task oriented and "sticks to the task" of providing estate information, whereas she in the relation oriented version ${ }^{6}$ also makes use of social dialogue, including small-talk.

As to the relation oriented version with the character's engaging in small-talk, which is a central social feature in communication between humans, Bickmore observes that this evoked strong - and diverging - reactions. Several subjects "reported liking the social dialogue aspects of the interaction: 'It wasn't just real estate talk, so I felt like it made her more human' ... 'It sounds like she's on your side when she says things are expensive"' (ibid., p.84). Other subjects “... clearly did not like REA's small talk at all: ... 'I come in and I shop and I get the hell out. She seemed to want to start a basis for understanding each other"' (ibid., p.85).

Furthermore, Bickmore \& Cassell [18] attempted to relate the varying user reactions to the user characteristic dimension of introversion-extroversion. A significant difference showed up in that "overall extroverts liked REA more when she used social dialogue, while introverts liked her more when she only talked about the task" (ibid., p.21).

\footnotetext{
5 "The task condition" in Bickmore's terminology.

${ }^{6}$ "The social condition" in Bickmore's terminology.
}

\subsection{A Character Enhanced Program for Coaching Indi- viduals' Physical Training}

Also Bickmore's [13] studies of the latter developed agent Laura indicates that user appreciation - both of a character as such, and of various social features in such a character - range widely. In Laura, or "the exercise advisor", more sophisticated relational and social attributes are modelled. She comes with FitTrack, a computer program designed to support students who wanted to increase their physical activity, and as in the case of REA, there are two versions of Laura. The "non-relational version" and the "relational version" differ from one another in that the latter models a number of verbal and nonverbal relational behaviours (e.g. an increase over time in frequency of smiles, coming closer, making gestures; engaging in small-talk, and so on).

As to the overall idea of conversing with and relating to an animated character, participants in Bickmore's studies reported strong opinions, positive as well as negative, for instance "It was a really, really great idea to have some kind of animated character because it make you feel like you're actually talking to a person rather than having words on the computer screen" versus "Laura is NOT a real person, and therefore I HAVE NO RELATION WHATSOEVER WITH HER!" (ibid., pp.184-85).

Specifically, the responses towards Laura's social orientation varied from "Laura and I trust one another", "My relationship with Laura is very important to me" and "I like talking to Laura, especially those little conversations about school, weather, interests ... She's very caring." (ibid., pp.184-89) to "I felt like I was talking to a robot, to a machine" and "I liked all of the software except for the animated conversation thing" (ibid., pp. 185-86).

Furthermore, the same general tendency as in the case of REA was found in that introverts tended to prefer the nonrelational version and extroverts tended to prefer the relational version.

\subsection{Brief Summary}

The four studies related offer a picture of mixed attitudes both towards character enhancement as such and towards social orientation in pedagogical characters. Furthermore, the studies indicate that certain user characteristics are involved in this picture, yet none of the studies explores user characteristics related to individuals' approaches to knowledge and learning. This is the contribution from the study now to be presented, which thereby represents an attempt to situate this kind of research more firmly in the educational domain.

\section{METHOD}

\subsection{Participants and Materials}

Ninety 12-15 year-old school children, 48 girls and 42 boys, from a Swedish secondary school, participated in the study, which was organized in the context of their regular arts lesson. The students came from nine different teaching groups, and all students had some familiarity with educational programs making use of virtual characters. Nearly all students in the groups participated, seemingly keen to participate. Some groups even organized a queuing system for themselves. 
For the study, two dummy versions of a scenario-based multimedia program for elementary school had been developed. In the program the learner takes the role of a journalist at a magazine who is sent on various missions to European countries in order to do article research. The two versions included (i) an introduction module where a first mission is presented and also information about the instructor and learning companion, respectively (for the instructor and companion version, respectively) and (ii) a module where the student shall chose an instructor agent or a companion agent from eight visually different animated pedagogical characters.

\subsection{Cognitive style Instrument: Attitudes Toward Think- ing and Learning Scale (ATTLS)}

The Attitudes Toward Thinking and Learning Scale (ATTLS) was developed by Galotti, Clinchy, Ainsworth, Lavin \& Mansfield [20] with the purpose to assess the extent to which an individual approaches knowledge in a separate and a connected way, respectively. To expand on the brief explanation earlier in this text, a connected approach towards knowledge involves trying to understand other people's views, theories, arguments, opinions, etc. by relating them to the experiences and background of the people in question. Who the person is in terms of life experiences, personality, etc., and why and how she/he has arrived at her/his argument is seen as relevant by this kind of learner. A separate approach towards knowledge, on the other hand, involves a more objective, analytical and detached evaluation of theories, arguments and opinions. This kind of learner finds it important to keep factuality and person apart, and prefers to focus on a theory, argument or opinion as such regardless of who the person is behind it. In a separate approach to knowledge, objectivity is a main value of a discussion or standpoint, whereas in a connected approach it is regarded as positive to involve one's own and other people's personal experiences in a discussion or standpoint [20].

There are connections to another, quite renowned cognitive style scale, namely the holistic versus serialist learners by Pask [26]. Holistic learners tend to seek an overall framework in an explorative and not strictly systematic, way. In this search they tend to appreciate and make use of enrichment data, such s for instance information on a speaker's background and experiences which he or she uses to develop and build associations. Serialist learners build their overall picture in a more systematic way, piece by piece, preferring the simplest possible connections between items of knowledge, not wanting to add any 'enrichment' data ('distracting data'), more as distracting (ibid.)

The ATTLS instrument consists of 10 statements that represent a connected way of knowing (e.g. "I am always interested in knowing why people say and believe the things that they do", "I like to understand where other people are 'coming from', what experiences have led them to feel the way they do") and 10 statements that represent a separate way of knowing (e.g. "It's important for me to remain as objective as possible when I analyse something", "I value the use of logic and reason over the incorporation of my own concerns when solving problems") [20]. Participants are asked to indicate how much they agree with each statement on a 7-point Likert scale that ranges from 1, strongly dis- agree, to 7, strongly agree. Scores are then calculated. Furthermore, calculating the differences between participants' scores on the two scales, participants with large differences can be classified as highly connected (HighC) or highly separate $(H i g h S)$ in their approach towards knowledge ${ }^{7}$.

\subsection{Procedure}

The three experimental leaders ${ }^{8}$ presented themselves to the group as coming from the university and working with research on educational media for the future. Students were then told that they were welcome to participate in a study. It was emphasized that the main purpose was to listen to students' opinions of various aspects of a program that they would be asked to try out and that they were fully anonymous. The experimental leaders did not mention who created the program. The students were asked to come, one at a time, to a small room behind the classroom where the session took place. In most cases all students in the group participated.

After the student had progressed through the program and reached the choice-of-character module came the part of the session that dealt with the preferences regarding visual style of characters, and articulations of these preferences ${ }^{9}$. Thereafter came the session part that is central for this article, namely the one that regards (i) attitudes towards virtual characters in pedagogical programs and (ii) attitudes towards a strictly task oriented character versus a more social or relation oriented character.

For assessing attitudes towards digital pedagogical characters (character enhancement) in general, students were provided with a 1-7 scale, where 1 stands for this being a very bad idea and 7 stands for this being a very good idea. The participants were also asked to motivate the score they gave.

Thereafter one of the experimental leaders presented two scenarios: (i) a scenario with an instructor/companion that focuses on the task at hand and sticks to this and (ii) a scenario with an instructor/companion that apart from working on the tasks also supplies information about him or herself, tells about former missions, her/his family and friends, her/his interests, and so on. ${ }^{10}$ Participants were then asked which of the two characters they would prefer. Thereafter they were asked to motivate their choice. Finally, the cognitive style inventory was completed.

The total time for a session was on average eighteen minutes. After completion, the participant was offered refreshment, was debriefed and thanked for valuable help.

\subsection{Hypotheses}

Firstly we wanted to investigate students' attitudes towards character enhancement in general, and towards relation oriented pedagogical characters in particular. Our expectation, on the basis of previous studies, was that some variation would show up. Secondly, we wanted to investigate

\footnotetext{
${ }^{7}$ In a psychometric assessment internal reliabilities for the scales were .83 for the CK scale and .77 for the SK scale.

${ }^{8}$ One ran the program and assisted the students; one observed choices and took notes; one conducted the interviews.

${ }^{9}$ Reported in [24].

${ }^{10}$ The exact wordings differed in details depending upon whether the student had been using the companion version or instructor version.
} 
whether attitudes could be related to cognitive style as assessed by ATTLS questionnaire. The following hypotheses were put forth:

- $\quad$ that subjects classified as HighC would tend to have a more positive attitude towards character enhancement than subjects classified as HighS,

- $\quad$ that subjects classified as HighC would tend to prefer relation oriented characters to task oriented characters,

- $\quad$ that subjects classified as HighS would tend to prefer task oriented characters to relation oriented characters.

\section{RESULTS}

\subsection{Target Groups for the Analyses}

$H i g h C$ subjects were defined as those in the highest quartile as to the difference $(D)$ between $\mathrm{C}$ - and S-scores $(n=22$; $18.0<=D<=41.0$ ). HighS subjects were defined as those in the lowest quartile regarding the difference $(D)$ between $\mathrm{C}$ - and S-scores $(n=22 ;-31.0<=D<=1.0)$.

\subsection{Attitudes Towards Virtual Characters in Pedagogical Programs}

As can be seen in Fig. (1), a majority $(80 \%, n=70)$ of the participants had a positive attitude towards the idea of virtual characters in pedagogical programs (score $5,6 \& 7$ on the Likert-scale where 7 stood for "this is a very good idea" and 1 stood for "this is a very bad idea"). Some representative comments were: "It's a good idea because sometimes it's boring to play alone"; "Good, because you feel you have someone along, it looks like a human being or how to put it"; "Good, it can be interesting to see how it reacts towards you, how it behaves towards you"; "It's a really great idea, it'll be more fun then"; "A character is more fun than only text-boxes"; "It's better with a figure that talks to you than only a voice"; "It's a good idea because then one doesn't have to be alone"; "It's a good idea, it can help you to enter the program".

\section{Frequency Chart:}

Rating of the 'pedagogical agent idea'

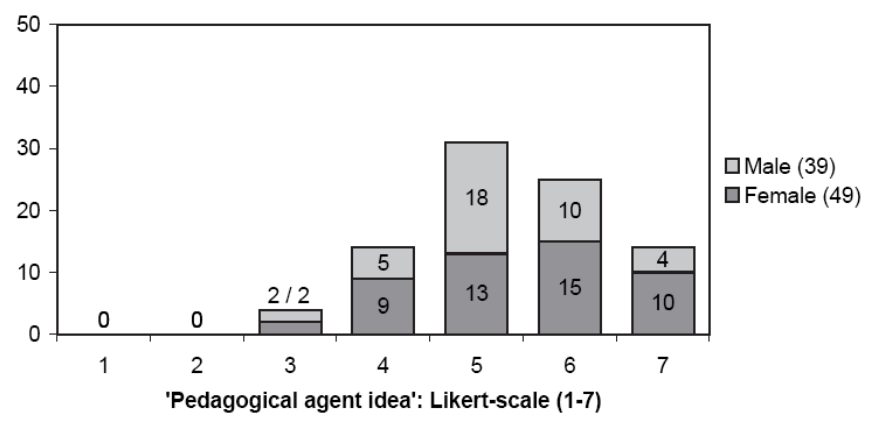

Fig. (1). Frequency chart describing the rating of the 'pedagogical agent idea' for the whole group of participants with males and females separated. There was no significant difference between the sexes regarding the ranking of the 'pedagogical agent idea' (independent samples two-tailed t test with pooled variances $(d f=86)$ : $t_{\mathrm{obt}}=0.948, t_{0.05} \approx 1.99 ; t_{\mathrm{obt}}<t_{0.05}$ ).

A minority $(20 \%, n=18)$ of the participants gave lower scores (3 or 4 on the Likert-scale), where some expressed doubtfulness or negative attitudes towards virtual characters in pedagogical programs: "I don't think it matters really whether there is such a character or not"; "It seems tiresome, it's easier if you're allowed to do things yourself, it'll probably only complain all the time"; "I never play computer games, I find the character idea questionable".

No participants used the lowest part of the scale (1 or 2 on the Likert-scale). A possible reason could be that participants assumed that the experimental leaders were positive towards the concept as they presumably worked within the area, and out of tactfulness did not answer very critically. However, a positive attitude was manifest in a majority of the participants, a result reminding of the study by [17] who noticed a "general youthful enthusiasm".

\subsubsection{Scores Given By Participants Classified as HighC and HighS}

Fig. (2a) shows the rating of the 'pedagogical agent idea' (Likert-scale: 1-7) given by HighC and HighS participants. A statistically significant difference was found between the two groups (independent samples two-tailed $t$ test $(d f=42)$ : $\left.t_{\mathrm{obt}}=2.32, t_{0.05}(42) \approx 2.02 ; t_{\mathrm{obt}}>t_{0.05} ; p \approx 0.025\right)$. Fig. (2b) shows a scatterplot for the overall correlation (Pearson correlation; $r=0.264$ ) between the ATTLS difference scores and the rating of the 'pedagogical agent idea' (Likert-scale: 1-7). A statistically significant correlation was found between the ATTLS difference scores and the rating of the 'pedagogical agent idea' ( $t$ test on $r(d f=84): t_{\text {obt }}=2.54, t_{0.02}(84) \approx 2.02$; $\left.t_{\mathrm{obt}}>t_{0.02} ; p \approx 0.014\right)$. Rating of the 'pedagogical agent idea' for
highC \& highs participants (ATTLS-score)

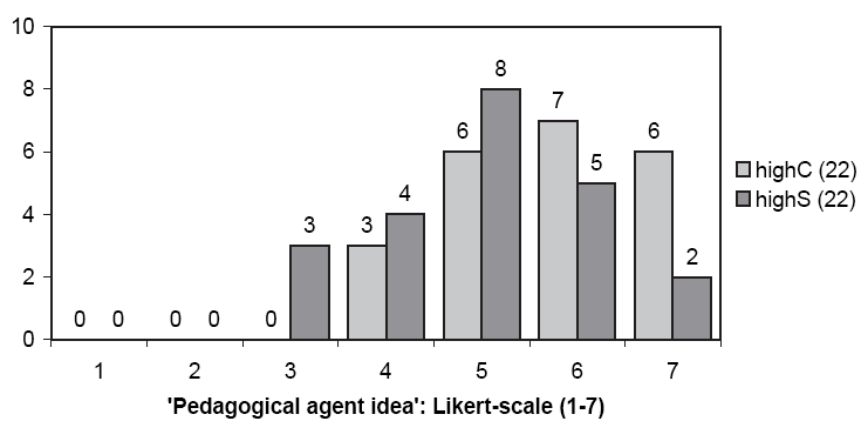

Fig. (2a). Frequency chart describing the rating of the 'pedagogical agent idea' (Likert-scale: 1-7) for HighC and HighS participants (given by the ATTLS difference scores).

That is, there is support for the hypothesis that HighC and HighS participants differ in their attitudes towards character enhancement, specifically that HighC subjects tend to have a more positive attitude towards character enhancement than HighS subjects.

\subsection{Attitudes Towards Relation Oriented Versus Strictly Task Oriented Pedagogical Characters}

Participants were asked to choose which kind of pedagogical character they would prefer and then asked to motivate their choice. Fig. (3) shows the distribution of all participants, where $42 \%(n=37)$ of the participants chose a strictly task oriented character and $58 \%(n=51)$ chose a relation oriented pedagogical character. ${ }^{11}$

\footnotetext{
${ }^{11}$ That is task and relation oriented character.
} 


\section{Correlation between ratings of the 'pedagogical agent idea' and the 'ATTLS difference scores'}

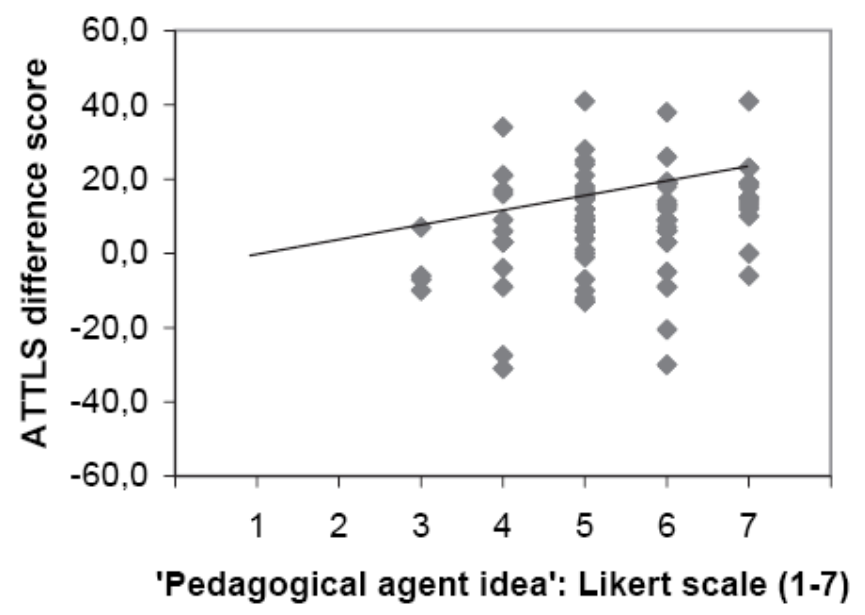

Fig. (2b). Scatterplot of the correlation between the rating of the 'pedagogical agent idea' (Likert-scale: 1-7) and the ATTLS difference scores. Regression line in $\operatorname{red}(\hat{Y}=3.47 X-10.1)$.

\section{Frequency Chart: Communicative style preferences}

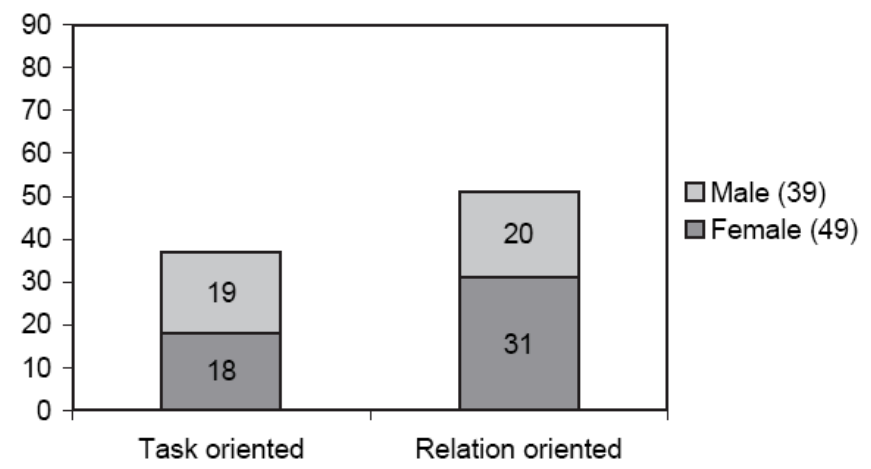

Communicative style: Task oriented - Relation oriented

Fig. (3). Frequency chart describing the communicative style preferences for the whole group of participants with sexes (males and females) separated. There was no significant difference between the sexes regarding communicative style preferences $\left(p\left(\chi^{2}\right.\right.$ test $\left.)=0.258\right)$.

As to the arguments for their choice, 17 participants motivated their choice of a relation oriented character in terms of it being more fun, nice or interesting, without developing the argument any further. Another 18 participants developed the argument as follows: the reason that it is nicer and more fun with a relation oriented character is that you get to know the character more. Some explicitly spoke about the importance of personal relations. Eight participants motivated their preference for a relation oriented character in terms of this being more playful and easy-going. A task oriented character, it was held, would make the task too serious and hard. Another four participants motivated their preference for a relation oriented character in terms of what is normal/common. Two of those thought, that the relation oriented character is more interesting because it is "not so common", whereas two found the relation oriented character "more normal and common".

All arguments in favour of a strictly task oriented character, notably, were negatively formulated, as arguments against a relation oriented character. The three most common categories of arguments, each occurring in seven instances, are related to one another. Seven participants held that a relation oriented character would be trying, tiresome and a nuisance. Another 7 pointed at the risk of getting distracted by a relation oriented character, and a third group of 7 participants spoke of a relation oriented character as one that does unnecessary or meaningless things instead of focusing on what is important. Another 5 participants emphasized that the character is a computer character and not a human being, and that they therefore did not want to know personal things about it.

In summary, the views on whether a relation oriented character are a good idea or not, clearly diverged.

\subsubsection{Preferences in Participants Classified as HighC and HighS}

As seen in Fig. (4), 14\% $(n=3)$ of the participants classified as HighC chose a strictly task oriented character and $86 \%(n=19)$ of them chose a relation oriented character. For participants classified as HighS the numbers were $73 \%$ $(n=16)$ choosing a strictly task oriented character and $27 \%$ $(n=6)$ choosing a relation oriented character. The results were significant at $p\left(\chi^{2}\right.$ test $)<0.001$. Thus, there were strong significant differences in choices, both for HighC participants and for HighS participants that support the hypotheses. HighC participants tended to prefer relation oriented characters to task oriented characters, whereas HighS participants, to the contrary, tended to prefer strictly task oriented characters to relation oriented characters.

\section{Preferences for character's communicative style for highc \& highs participants (ATTLS)}

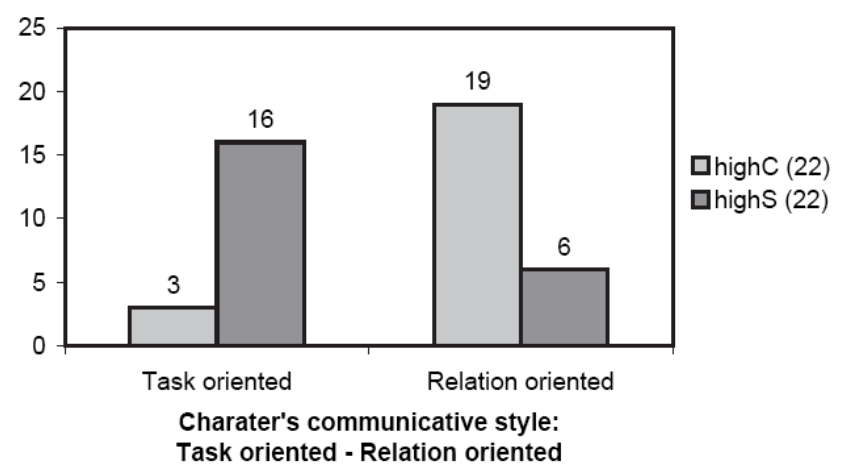

Fig. (4). Frequency chart describing the preference for the character's communicative style (task oriented - relation oriented) for the HighC and HighS participants (according to the ATTLS difference scores).

\section{DISCUSSION}

The study presented in this article confirms what a few other studies have also shown, namely that there are considerable individual differences in attitudes towards character enhancement of digital learning environments, and specifically in attitudes towards relation oriented characters. Moreover, the results of the study presented indicate that 
such attitude differences can be related to differences in cognitive style as assessed by the ATTLS inventory. This is a cognitive style aspect that relates more explicitly to individual's approaches to knowledge and learning than do user characteristics such as introvertness-extrovertness, passiveness-activeness and control orientation that have been explored in previous studies.

Overall the study presented, together with other studies, suggests a need to cater for individual differences when designing social interfaces (cf. [15]), in particular in relation to the design of the digital characters that are becoming increasingly common in digital learning environments.

But how should the matching process proceed if there are, for example, different types of digital pedagogical characters in an environment? One possibility of matching is to let the learners fill out cognitive style inventories, such as the ATTLS inventory and on the basis of the outcome be assigned different virtual pedagogical characters. However, there are objections to such an approach. Findings of user or learner variability are statistical correlations regarding groups of users. It is questionable to base strategies for dealing with individuals on such findings. Furthermore, there is evidence that cognitive style characteristics can be context dependent [21]. (In line with these two participants in our study explicitly remarked that the ideal would be to have both kinds of pedagogical characters available to choose from depending upon mood: "Sometimes one would feel like chatting more, but sometimes one would prefer a companion that is quiet and sticks to the task. The best would be if one could choose between companions that have different personalities". "It depends. Sometimes I would like one that is talkative and social, but sometimes I cannot stand that and want to be spared from it").

Generally we therefore think that users should choose for themselves - however from an adequate variety or manifold of pedagogical characters. Likewise in products that use multiple characters (teams of characters, multiple agent systems, etc.), it is important that an adequate diversity is supplied. In order to obtain this, one way to go is to communicate research results from user studies, such as the ones reported in this paper, to inform instructional designers.

As to the option "pedagogical character" versus "no pedagogical character", we agree with Laurel [27] in her recommendation that "only users who want to use agents should have them, others should have other choices" (ibid., p.209). However, the recommendation may be of less importance in the case of educational software for young people. The result of the study presented in this paper as well as of several other studies on children, show positive attitudes towards the general idea of pedagogical characters in a large majority of children $[11,17]$. Furthermore, digital characters are integrated and natural aspects of the digital life of young people, with many popular consumer interfaces, such as instant messaging clients, on-line forums, console games and computer games, featuring digital characters.

That is, we believe one may settle for a character solution - nevertheless it is important to make sure there is a diversity of personalities and communicative styles - as well as visual styles [24] - represented in the characters. (Recall how somewhat older children were reluctant towards charac- ters that suited somewhat younger children well in the StoryStation project described above).

To aim for a solution with a variety of characters - in personality, communicative style and visual style - is to aim for a solution that fully exploits the power of a character enhanced digital environment in contrast to the conventional real world paradigm of "one class - one teacher". In the latter case the match/mismatch between the teacher's teaching style and different students' learning styles inevitably benefits some students but not others [21]. With the advent of well-designed digital environments one may obtain better matches for more students.

\section{ACKNOWLEDGEMENTS}

The authors wish to acknowledge the support of the Swedish Research Council (Vetenskapsrådet). Many thanks to Martin Jonasson for collaboration in the design and carrying through of the study. Not the least, thanks to all student participants in the study, and to helpful teachers and school leaders at the participating schools.

\section{REFERENCES}

[1] Dowling C. The socially interactive pedagogical agent within online learning communities. ICCE 2002; 1: 20-34.

[2] Mclnerney D, Van Etten S, Eds. Research on sociocultural influences on motivation and learning. Greenwhich: Information Age Publishing 2000.

[3] John-Steiner V, Mahn H. Sociocultural contexts for teaching and learning. In: Reynolds A, William M, Miller G, Eds. Handbook of Psychology: Educational Psychology. New York: John Wiley and Sons 2003; Vol. 7: pp. 125-51.

[4] Donald M. Origins of the modern mind: Three stages in the evolution of culture and cognition. Cambridge, MA: Harvard University Press 1991.

[5] Moreno R. Immersive agent-based multimedia environments: Identifying social features for enhanced learning. In: Niegemann $\mathrm{H}$, Leutner F , Brünken R, Eds. Instructional design for multimedia learning. Münster, Germany: Waxmann 2004, pp. 9-18.

[6] Atkinson R, Mayer R, Errill M. Fostering social agency in multimedia learning: examining the impact of an animated agent's voice. Contemp Educ Psychol 2005; 30: 117-39.

[7] McQuiggan S, Lester J. Learning Empathy: a data-driven framework for modeling empathetic companion agents. proceedings of the 5 th international conference on autonomous agents and multiagent systems (AAMAS'06). Hakodate: Japan 2006, pp. 961-68.

[8] Kim Y, Baylor A. A social cognitive framework for designing pedagogical agents as learning companion. Educ Technol Res Dev 2006; 54(06): 569-96.

[9] Höök K, Persson P, Sjölinder M. Evaluating users' experience of a character-enhanced information space. AI communications. Eur J Artif Intell 2000; 13(3): 195-212.

[10] Lester J, Callaway C, Grégoire J, Stelling G, Towns S, Zettlemoyer L. Animated pedagogical agents in knowledge-based learning environments. In: Forbus K, Feltovich P, Eds. Smart machines in education. Menlo Park, CA: AAAI/MIT Press 2001, pp. 269-98.

[11] Hall L, Vala M, Webster M, Woods S, Gordon A, Aylett R. FearNot's appearance: reflecting children's expectations and perspectives. Proceedings of the International Conference on Intelligent Virtual Agents 2006 (IVA'06). Marina Del Rey: CA 2006.

[12] Hietala P, Niemirepo T. The competence of learning companion agents. Int J Artif Intell Educ 1998; 9: 178-92.

[13] Bickmore T. Relational agents: effecting change through humancomputer relationships. PhD thesis, Media, Arts \& Sciences, Massachusetts Institute of Technology. Retrieved May 192004 Avalaible from: http//web.media.mit.edu/ bickmore/bickmore-thesis.pdf

[14] Moundridou M, Virvou M. Evaluating the persona effect of an interface agent in a tutoring system. J Comput Assist Learn 2002; 18: 253-61.

[15] Baylor A. The impact of pedagogical agent image on affective outcomes. Proceedings of the workshop on affective interactions: 
computers in the affective loop at the 2005 international conference on intelligent user interfaces (IUI 2005). San Diego: CA 2005.

[16] Moreno R, Mayer R, Spires H, Lester J. The case for social agency in computer-based teaching: do students learn more deeply when they interact with animated pedagogical agents? Cogn Instruct 2001; 19: 177-213.

[17] Robertson J, Cross B, Macleod H, Wiemer-Hastings P. Children's interactions with animated agents in an intelligent tutoring system. Int J Artif Intell Educ 2004; 14: 335-57.

[18] Bickmore T, Cassell J. Social dialogue with embodied conversational agents. In: van Kuppevelt J, Dybkjaer L, Bernsen N, Eds. Natural intelligent and effective interaction with multimodal dialogue systems. New York: Kluwer Academic Press 2004.

[19] Rickenberg R, Reeves B. The effects of animated characters on anxiety, task performance, and evaluations of user interfaces. Proceedings of the CHI 2000 conference on human factors in computing systems (CHI'00). New York: ACM Press 2000, pp. 49-56.

[20] Galotti K, Clinchy B, Ainsworth K, Lavin B, Mansfield A. A new way of assessing ways of knowing: the attitudes towards thinking and learning survey - ATTLS - Statistical Data Included. Sex Roles 2001; 40(9/10): 745-66.
[21] Sternberg R. Thinking styles. Cambridge: Cambridge University Press 1997.

[22] Ford N, Chen Y. Matching/mismatching revisited: an empirical study of learning and teaching styles. Br J Educ Technol 2001; 32: $5-22$.

[23] Gulz A. Social enrichment by virtual characters - differential benefits. J Comp Assist Learn 2005; 21(6): 405-18.

[24] Gulz A, Haake M. Social and visual style in virtual pedagogical agents. Proceedings of the Workshop on Adapting the Interaction Style to Affective Factors at the 10th International Conference on User Modelling 2005 (UM’05), Edinburgh, Scotland 2005.

[25] Haake M, Gulz A. A look at the roles of look \& roles in embodied pedagogical agents - a user preference perspective. Int J Artif Intell Educ 2009; 19(1): 39-71.

[26] Pask G. Styles and strategies of learning. Br J Educ Psychol 1976; 46: $128-48$.

[27] Laurel B. Interface agents: metaphors with character. In: Friedman B, Ed. Human values and the design of computer technology stanford, CA: Cambridge University Press 1997, pp. 207-19.

(C) Gulz and Haake; Licensee Bentham Open.

This is an open access article licensed under the terms of the Creative Commons Attribution Non-Commercial License (http://creativecommons.org/licenses/by$\mathrm{nc} / 3.0 /$ ) which permits unrestricted, non-commercial use, distribution and reproduction in any medium, provided the work is properly cited. 